\title{
The effect of prior knowledge and decision-making style on the online purchase decision-making process: A typology of consumer shopping behaviour
}

\author{
Sahar Karimi, ${ }^{\text {a,b }}$ K. Nadia Papamichail ${ }^{\mathrm{a},{ }^{*}}$ \& Christopher P. Holland ${ }^{\mathrm{a}}$ \\ ${ }^{a}$ Manchester Business School, The University of Manchester, Booth Street East, Manchester, \\ M15 6PB, UK \\ bEdge Hill University, St Helens Rd, Ormskirk, Lancashire L39 4QP, U.K.
}

\begin{abstract}
This paper provides an empirical typology of online decision-making purchasing behaviour. The study explores how the online purchase process is affected by individual decision-making style and knowledge of product. Drawing from the decision analysis and consumer behaviour literatures, we present a typology of online purchase decision-making behaviour and introduce four archetypes of online consumers. A number of experiments have been conducted in two online settings: retail banking and mobile networks. Based on an extensive video analysis, we have captured four process-related dimensions (number of cycles, duration, number of alternatives and number of criteria) using a business process modelling approach. Significant differences in all process-related dimensions were found across the four archetypes. The study improves understanding of the different types of online consumers and their process outcomes. The findings are useful for online retailers seeking to improve the way they support the four archetypes of online shoppers throughout the decision-making purchasing process.
\end{abstract}

Keywords: B2C E-commerce; online shopping; online purchase decision-making processes.

\footnotetext{
*E-mail: nadia.papamichail@mbs.ac.uk＿Tel: +44 (0)161 2756539
} 


\section{Introduction}

An increasing number of consumers are engaging in online retailing interactions [17]. Even though electronic commerce is expanding rapidly [51], our understanding of econsumer behaviour is still limited [25]. Internet purchase behaviour does not necessarily follow traditional consumer purchase behaviour [65]. Therefore, developing new models of consumer behaviour will help businesses to enhance their understanding of their consumers and market segments, which in turn will lead to increased profitability [97].

There have been several attempts to model and interpret online purchase behaviour [16, 22, 50, 70, 109]. A number of studies have explored behavioural variation, taking into account individual characteristics such as perceived risk [63], trust [20, 38], Web skills [56, $65]$ and involvement $[4,91]$. However, there are still gaps in our knowledge of how different individuals engage in purchase decision-making processes and how such processes unfold. Therefore, there is a need to shift our focus from investigating adoption of Internet shopping to exploring actual online consumer behaviour and identifying distinctive groups of consumers based on their decision making styles. Two variables, consumer knowledge and decision making style, are used in this study to develop a typology of online consumers.

Consumers' knowledge of products is an individual characteristic that has been shown to have an effect on the purchase process [76]. However, the findings in the literature are contradictory. Some studies have shown that knowledge of product influences online behaviour $[44,76]$ whereas other studies do not show any significant relationship [6]. It has been suggested that these contradictory results are due to the impact of other individual characteristics $[9,74]$. Decision-making style, which can be defined as the tendency to satisfy or maximize a decision, is an individual characteristic that has been shown to be a predictor of decision-making behaviour $[53,102]$ and a determinant factor in the way decision making processes unfold $[18,102]$. Taking into account both characteristics can further explain the variations in the purchase decision making process. 
This paper investigates the differential effects of decision-making style and knowledge of products on purchase decisions. We classify consumers into four archetypes, taking into account decision-making style (maximizers/satisficers) and knowledge of products (high/low). The behaviour of each archetype in terms of decision-making process outcomes is examined. Previously, process outcomes such as the number of cycles, the duration of the decisionmaking process, the number of criteria and alternatives considered by customers have been used to assess the purchase decision-making process $[18,98,102,106,120]$.

The main aim of this study is to explore online purchase decision-making processes. The objectives are:

- to develop a typology of online behaviour based on archetypes of online consumers defined by decision-making style and knowledge of product

- to empirically demonstrate differences in the decision making behaviour exhibited by each archetype

- to present a process modelling method for coding the consumer decision-making process

This paper informs the literature by showing the fundamental differences in the decision-making behaviour of each archetype of consumers. It is a broad study that measures the behaviour during all the stages of the purchase process, rather than using the common approach of focusing on search and evaluation only. By improving our understanding of different consumer segments and variations in their behaviour, it will "assist service providers in designing customized websites for competitive advantage" [91 p. 51].

The structure of the paper is as follows. Section 2 discusses the literature on purchase decision-making processes, introduces our typology of consumer decision-making behaviour and presents our theoretical framework. Section 3 illustrates the research method and discusses our data collection process. It is followed by the data analysis section 4 , which discusses the approach used to model purchase decision-making processes and the 
measurements applied. Section 5 presents the results of this research followed by a conclusion and discussion of limitations and further research in section 6 .

\section{Background and conceptual development}

\subsection{An online purchase decision-making process model}

According to the consumer decision-making literature, a purchase decision is the behavioural pattern of a consumer who determines and follows a decision process comprising various stages in order to reach a choice [29, 31, 48]. The 'classical purchase behaviour model' is a linear model that illustrates the main stages of the purchase process. This model is based on several studies including those of Engel et al. [30], Howard and Sheth [48] and Nicosia and Mayer [79] and has been used as the standard model in consumer behaviour research (e.g. [111, 116]) and online consumer research [44]. It comprises the need recognition, information search, evaluation of alternatives, purchase and post-purchase stages.

The discipline of decision analysis provides a different perspective on how purchase decisions, which are one type of decision-making process, unfold. A widely used model of decision-making, introduced by Holtzman [47], includes three stages: formulation, evaluation and appraisal. The two phases of formulation and appraisal are important stages of any decision-making process $[35,47,81,95]$ but have been overlooked in the consumer decisionmaking literature. In the formulation stage, the decision problem is formulated in the mind of the decision-maker, alternatives are generated and criteria articulated. Appraisal is where the resulting choices are appraised. These stages are therefore included in the purchase process.

Decision-makers often skip steps or do not follow all stages in a linear form [82] and process instances often include divergences from the main route and iterations between stages [67]. Online purchase decision-making is a dynamic and highly flexible process. Decisionmakers are adaptive in the way they respond to decision tasks $[64,85,86]$. As the decision process unfolds, individuals make choices about the process and may follow different paths. This kind of flexibility has been defined as "the ability to adapt the process flow on demand through adding, skipping, or sequence reordering of process steps" [28, p. 330]. 
A new framework is presented in Figure 1 that is based on the literatures of consumer purchase decision-making and decision analysis.

--- Insert Fig. 1 around here ---

The framework synthesizes stages of the purchase process to provide prescriptive and descriptive views of online purchase decision-making processes. It extends the linear process models often used to describe decision processes. First, it supports the dynamic and constructive nature of this process by illustrating loops within the process. Second, it illustrates a prescriptive view in the sense that it includes a comprehensive set of stages. The framework is used to measure and identify key patterns of behaviour and variations in the way the purchasing process unfolds.

\subsection{A typology of online consumer decision-making behaviour}

Early research on purchase decision-making focused on decision tasks but there is less evidence on those decision-making characteristics that affect purchase decisions [103]. Recently, several studies have discussed individual characteristics and their impact on the stages of the purchase decision-making process [18, 91, 108]. Prior consumer research included demographics or product-related characteristics that vary across individuals, such as product involvement and profile consumers [18]. However, our review of the literature indicated that decision making style and knowledge of product are important variables and there is little empirical research into their effects on online consumer behaviour.

\subsection{Variations in purchase behaviour}

The decision-making dependent variables of our study are (1) the number of cycles, (2) the duration, (3) the number of alternatives considered, and (4) the number of criteria. Previous research has shown that knowledge negatively influences the number of process cycles, duration [76] and performance of concept formation $[59,110]$. Decision making style in terms of maximization tendency positively influences the number of cycles in the decisionmaking process $[18,102]$ and duration [18]. Therefore, consumers' decision making style and 
knowledge of product affect their behaviours in terms of the four process-related dimensions identified above, which is discussed next.

\subsection{Decision making style}

The concept of 'satisficer' originates from Simon's seminal work on decision making styles [108]. In the decision-making literature, the tendency to maximize or satisfice has been found to have a direct impact on the decision process and can explain diversities in decisionmaking behaviour $[54,102]$. Maximizers seek the best possible result whereas satisficers opt for a good enough choice that meets some criteria. This aspect of decision-making style has only recently been examined in the online consumer behaviour literature. As Chowdhury et al. [18] have pointed out "very little empirical work has been done till now to understand the implications of this trait for consumer choice behaviour and decision-making processes" (p. 156).

When faced with a decision, maximizers search for more information and browse more intensively $[18,102]$. They perform an "exhaustive search of all possibilities" and analyse all the information available to them $[54,102]$. They actively seek to identify a larger number of alternatives [89] and their search behaviour is characterized by going forwards and backwards between choices. They consider a large number of criteria and engage in intensive comparison activities [102]. However, cognitive limitations increase the difficulty of decision tasks such as the evaluation and comparison of all alternatives [53, 54]. They also tend to underestimate the time resources they need to allocate to a task [8]. Maximizers therefore engage in longer (time-wise) decision processes with more cycles than satisficers.

Satisficers engage in 'satisficing' behaviour by searching for alternatives that are good enough [108], rather than attempting to reach some kind of optimal outcome. They are also highly selective in using and processing information [14] especially in online platforms [18], which reduces the number of alternatives they consider. Satisficers will therefore reduce their search effort in terms of cycles and time $[18,102]$ and decrease their analysis and evaluation

effort in terms of alternatives [53, 54] and criteria [102] compared to maximizers. Overall, 
satisficers perform less intensive research, have a smaller consideration set and allocate less time to decision tasks during online shopping [18]. This leads to the formulation of the following hypotheses:

H1: Decision making style has an effect on decision-making process outcomes.

H1a: Satisficers engage in decision-making processes with a lower number of cycles, compared to Maximizers.

H1b: Satisficers engage in decision-making processes of shorter duration, compared to Maximizers.

H1c: Satisficers engage in decision-making processes with a lower number of alternatives, compared to Maximizers.

H1d: Satisficers engage in decision-making processes with a lower number of criteria, compared to Maximizers.

\subsection{Knowledge of product}

Knowledge of product affects purchase behaviour $[12,14,21,76,77,93]$ and has been shown to influence the information search stages $[11,76,94,101]$ and the information processing stages $[2,9,11]$. However, previous research results on the effects of knowledge on search effort have been contradictory. Some researchers have suggested a negative relationship between amount of knowledge and amount of external search [76] but other findings do not support such a relationship [6, 62]. Malhotra [74] explains this equivocal result by stating that consumers with high knowledge lack the motivation to search for information while those with low level of knowledge are not capable of searching and evaluating the information [9]. However, it might be explained in more detail through experimental research that examines the effect of product knowledge on a range of purchase decision making variables, and also in conjunction with the decision making style of individuals.

Consumers with high levels of knowledge are more aware of their preferences and tend to start with a smaller considered set of alternatives $[11,21]$. They tend to have a preconceived 
idea of what evaluation criteria they should use in order to evaluate alternative products [21]. With high levels of knowledge, these consumers are confident in their own ability to undertake information searching tasks [101]. They are capable of effortlessly assessing information $[2,21]$, which can reduce their overall evaluation time and number of cycles. Low knowledge holders are limited in their ability to collect and assimilate relevant information for evaluating options [74]. They therefore engage in more intensive processes in terms of cycles and time. As they are not aware of suitable options and relevant decision criteria, they consider a larger set of alternatives and criteria. Thus, we propose the following hypotheses:

H2: Knowledge of product has an effect on decision-making process outcomes.

H2a: Consumers with a low level of knowledge of product engage in decision making processes with a higher number of cycles, compared to consumers with a high level of knowledge of product.

H2b: Consumers with a low level of knowledge of product engage in decision-making processes of longer duration, compared to consumers with a high level of knowledge of product.

H2c: Consumers with a low level of knowledge of product engage in decision making processes with a higher number of alternatives, compared to consumers with a high level of knowledge of product.

H2d: Consumers with a low level of knowledge of product engage in decision making processes with a higher number of criteria, compared to consumers with a high level of knowledge of product.

\subsection{Archetypes}

By combining the decision-making style with the level of knowledge within a particular decision-making setting, we introduce four consumer archetypes as shown in Table 1. Consequently, the four archetypes exhibit different behaviours in terms of the four processrelated dimensions identified.

--- Insert Table 1 around here --- 
Archetype 1 users (Satisficers with low level of knowledge) will engage in less intensive processes in terms of number of cycles, duration, number of alternatives considered, and number of criteria compared to both maximizer archetypes 3 and 4 as their satisficing behaviour leads them to a more efficient process. Due to their limited ability to collect and assimilate relevant information for evaluating options, they are expected to perform more search than Archetype 2. The combination of satisficing behaviour and a high level of knowledge for Archetype 2 users (Satisficers with high level of knowledge) reinforce the propensity of this archetype for efficiency. Their high level of knowledge combined with their satisficing search strategy will naturally limit the amount of search they carry out [74]. We expect Archetype 2 to engage in less intensive activities for all measures of search effort compared to the other archetypes. On the other extreme, we expect Archetype 3 (Maximizers with low level of knowledge) to engage in intensive search activities for all decision process outcomes. Archetype 4 (Maximizers with high level of knowledge) is expected to expend a lower search effort than Archetype 3. Their maximizing decision-making style means that they have feelings of regret and fear of overlooking good alternatives or not identifying existing high quality options [102]. We therefore expect this archetype to invest emotionally in decisions and engage in processes with higher duration, number of cycles, alternatives and criteria compared to satisficers in archetypes 1 and 2.

In summary, we have argued that the decision analysis and consumer behaviour literatures have not fully explored the additive effects of decision making style and product knowledge on online consumer purchasing behaviour, and we expect significant differences in process-related outcomes amongst the four consumer archetypes. It is expected that maximizers will exceed satisficers for all dependent decision-making variables, i.e. maximizers will have a higher number of cycles, spend more time, consider more alternatives and evaluate more criteria than satisficers. Similarly, it is proposed that amongst maximizers and satisficers, those with low knowledge will expend more search effort than those with high knowledge for each of the dependent variables. 


\section{Research method and collection of data}

\subsection{Experiment design}

One of the best ways to trace a decision-making process is to track it as it unfolds so that the knowledge of the final outcome does not affect the perception [69]. In addition, observation of consumers as they follow the process facilitates the identification of different behavioural patterns [91]. Therefore, a method that allows for the recording of the process, in real time, is the best way to capture the process and identify decision-making patterns.

Video recording was used to capture the entire process as it occurs. It provides a "direct insight into process" and a "clear view of the flow of interaction" [119]. Similar experiments have also used video recording for modelling processes [45, 96], capturing the behaviour of Internet users [13], exploring decision-making processes [66] and analysing behavioural phases [119]. Other researchers have used logs of decision-makers' interactions [87]. Although logs can be used to illustrate the process that decision-makers follow, it does not adequately take into account the context in which the activity takes place [13] and does not capture the rationale behind actions.

After collecting the video recordings, we applied business process modelling techniques [82] based on UML activity diagrams $[1,15]$ to analyse the decision-making processes followed. Individual process models were then analysed for each participant and used to build an overall picture for the four archetypes shown in Table 1, in order to identify common patterns of behaviour within groups and test for differences between groups. A pilot study with three participants was conducted to ensure that decision-making processes could be codified by this method. Section 4.1 and section 4.2 discuss the modelling and coding method in detail.

\subsection{The research context}

In line with other studies that investigate online consumer behaviour (see for example $[4,33$, 84]), we are examining online decision-making behaviours in two sectors, banking and mobile phone networks. Purchase decision-making in both sectors is a rather complex and 
engaging process; it involves consideration of a number of alternatives and evaluation criteria. What differentiates online purchasing in the two sectors, though, is that in the mobile network providers sector, consumers examine tangible products plus service whereas in the banking sector they consider the service only. Together, these sectors represent important parts of the economy. In both markets, the distinction between products and services is blurred although the mobile phones market has a more physical tangible product in addition to the service element compared to banking. Both sectors also represent non-trivial purchases and therefore represent serious challenges to consumers who must think carefully about how to address the problem of choosing an individual supplier.

A growing body of the literature has examined the use of online banking by consumers $[37,41,49,90,99,117]$. Banking is a sector that has been greatly affected by the Internet [55]. In the UK, for example, consumers are increasingly searching online for information about financial products [121]. Complexity and the risk involved in the purchase of banking products/services, as well as the self-service nature of the Internet are characteristics of the online purchase decision-making processes in this sector. Consumers are expected to retrieve and make sense of complicated information and complete a purchase decision on their own. As banking institutions invest in their online interface, they need to understand the purchase behaviour of their consumers, their requirements and the difficulties that they encounter.

Mobile phones have become one of the most commonly used daily multipurpose and interpersonal consumer devices $[10,71]$. The mobile phone market is very dynamic with frequent technological and service changes, which take place in a highly competitive environment $[88,107]$. Mobile phone buyers need to choose a handset and services. Their decision criteria are complex [88] and the information gathering task is therefore demanding [115]. Fast changes in the market combined with the complexity of networks, tariffs and contracts make the comparison between different networks and the selection of the best value tariff difficult for consumers [115]. The size and continuing growth of the mobile phone market make it one of the most important global sectors in service marketing [24, 107]. 


\subsection{Procedure and task}

The research method consisted of video recording sessions, interviews and questionnaires. Experiments were conducted involving video sessions with fifty-five (55) individual participants. Participants sat at a computer and received a booklet including a questionnaire and task description. They were asked to fill in one questionnaire upon their arrival, covering questions on demographics, Internet usage skills, product and sector knowledge and maximization tendency. Internet usage skills were measured in order to ensure that all participants were capable of completing the task. Prior knowledge of the product and market was measured by two separate questions using a Likert scale. The maximization tendency was calculated using the measurement developed by Schwartz et al. [102] (see section 4.4).

Following the administration of the questionnaire, the participants were introduced to the task description. Twenty-five participants were asked to choose a current account and thirty individuals were tasked with the selection of a mobile phone package. Inclusion criteria for selecting the participants were their Internet usage skills and previous experience of online purchase. Prior to the experiment they were informed that the task was related to online purchase and they were expected to choose a product. They were not informed of the sector nor the product. They were then randomly assigned to one of the two scenarios. The participants were students enrolled in a $\mathrm{PhD} / \mathrm{MBA}$ programme and individuals working in academia and industry. In order for the task to be as realistic as possible participants were given no instructions on how to proceed. As they were sitting in front of a computer, a videorecording camera was located next to the participant, with the monitor in the camera's frame. A microphone was placed in front of them and was connected to the video recorder. This allowed a simultaneous collection of process data and verbal protocols. The think aloud technique $[5,26,58]$ was used to produce the verbal protocols. Participants were asked to stop when they had decided on their preferred product. At the end of the session, for verification purposes, a semi-structured interview was conducted with each participant. Questions were asked concerning their behaviour in different stages of the process to ensure 
the accuracy of the recorded video processes and also to identify issues that the participants did not raise verbally during the process.

Video recording and verbal protocols generate a large amount of data and therefore many instances of various behaviours. In this research, 19 hours and 7 minutes of video recordings were collected which resulted in the coding of 3,083 activities and 1874 transitions. Similar studies that have captured the purchase behaviour of participants by videoing their interactions with IT equipment have recruited eleven [58], eight [13] and eight [5] participants respectively. Byrne et al. [13], for instance, collected 5.75 hours of video files from eight participants. Protocol analysis of this type provides very rich data and sample sizes of up to 20 are the norm [114]. The researchers therefore argue that the sample size in this study is significantly larger than previous similar research. Comparison with sample sizes for random samples using questionnaires is not apt for this type of research [5, 104].

\section{Data analysis}

\subsection{Modelling approach}

Capturing the videoed process in a meaningful way requires the choice of the right modelling method. Decision-making processes that include an order of activities can be modelled using UML activity diagrams [46], a business process modelling method that shows the behavioural view of a process. It models the activities of a process and illustrates its flow and steps [15].

Other methods such as Petri Nets have also been used to model processes. However, UML activity diagrams have been found to be more suitable for activity-based processes [32, 87] and therefore were selected as the most appropriate modelling method for this research. Activity diagrams enabled detailed and systematic coding of the video data. An activity diagram (process model instance) was generated for each individual, illustrating all the activities performed and the flow of the process. After developing the individual processes, a 
general decision-making process model for each archetype of consumer was generated by bringing together the individual models of participants for each archetype group.

\subsection{Coding}

A verbal protocol can only be coded using a model or a theory for the decision process [92]. In this study, the coding scheme $[60,61]$ is based on the framework of Fig.1. Six roles have been identified which correspond to the six stages of Fig.1. Table 2 shows the stages and their corresponding roles. Purchase and post-purchase behaviour are excluded as the aim of this research is to examine the way a purchase decision-making process unfolds and leads to the choice of a product. Therefore, choice is the last stage considered. In addition, as the purchasing task was presented to all participants in the experiment, including the stage of 'need recognition' would be meaningless. All the roles (e.g. information seeker, evaluator) were defined prior to the modelling of the process.

\section{--- Insert Table 2 around here ---}

Consumers switch between different roles (e.g. information searcher, evaluator) and perform activities in order to reach the final goal of choosing a product. Roles are essentially the modules of the behaviour that interact with each other. They encompass a set of related activities to achieve the goal of that particular role [118]. An activity is essentially a behavioural item that is of interest. Cues have been used to identify activities. Cues can be classified into actions (e.g. navigation, clicks) and dialogues (e.g. saying something aloud).

The video data was coded using cues to identify activities undertaken by the participants, which were then assigned to roles. Fig. 2 shows part of the process model for one individual.

--- Insert Fig. 2 around here ---

It should be noted that the models are evolved by the consumer as the process progresses. Individuals dynamically decide on the next activity to perform. Thus, consumers 
follow different decision-making paths and follow different instances of the process. However, general patterns and a basic logic in decision-making can be identified for groups of individuals who follow common patterns of decision-making. Following the video sessions, interviews were conducted with the participants to discuss the flow of their activities. This was used to verify and confirm the flow of the activity diagrams. An additional output of the interviews was to establish which criteria were used by the consumers in their online purchase processes.

The reliability of the coding can be identified by consistency checks where another coder performs a partial coding of the same data [112]. This reliability check has been used in the studies of video recordings [19] and verbal protocols [36]. All the video recordings were coded by one of the authors. In order to check interpreter reliability, video recordings of $20 \%$ randomly selected participants were coded by two other coders. The second coder was involved in the project while the third coder was an independent judge. The coding scheme that defined different stages and roles was explained to the third judge. The number of differences found in terms of coded transitions were divided by the total number of codes. The second coder who was familiar with the research had a variation of $6 \%$ with the first coder. The independent coder also had a relatively small variation of 9\%. In line with the similar studies where the differences were resolved by discussion, the coders discussed each of the variations to resolve the differences. The coded process was also compared with the participants' own description in the interview to ensure a reliable interpretation of the process data.

\subsection{Decision making dependent variables}

Video data capture meant that the researchers could capture each stage of the decisionmaking process [57]. Previous research has examined the extent to which a decision process is exhaustive or intensive in terms of engaging in the decision making process, researching and evaluating alternatives and allocating time to the process $[18,102]$. Another indicator is the decision effort in terms of the attributes/criteria considered such as price and quality [40]. 
The four dependent variables are therefore the number of cycles, duration (i.e. the amount of time spent on the process), the number of alternatives and the number of criteria.

Process-activity diagrams illustrate the cycles between roles (also defined as iterations or transitions) [118]. These cycles indicate actual progress and constitute an important aspect of the analysis when studying decision making processes $[81,82]$. The number of cycles is calculated in terms of iterations or transitions between stages and it is indicative of the dynamic nature of the process.

Time duration is an important dimension of the decision-making process $[3,92,120]$. It is an important measure of online activities $[52,113]$. It has been argued that a longer duration visit could be the result of different factors such as confusing navigation, slow connection and load times. It could also indicate a certain level of difficulty in understanding the content or executing the shopping task. However, performing the experiment under the same conditions eliminates the impact of external factors such as slow connection. Therefore, the differences in duration are due to individuals' differences, such as their ability to locate relevant information and willingness to spend more time on the task in order to maximize their choice. In other words, the visitors to a website are continually making a "judgment as to the value of continuing on at a given site or clicking away" [43, p.38]. Therefore, if consumers remain at a site by choice, then there should be a value in exchange for their time. Time duration from the start of online purchasing to the choice of product is therefore a good indicator of behaviour that can be used to differentiate between individuals [113].

The decision-making process is shaped around the constructs of alternatives [27, 106] and evaluation criteria [76]. The number of alternatives, also termed the consideration set in the marketing literature, is calculated by counting the options considered. The number of evaluation criteria is a count of the attributes used to evaluate the possible choice options against each other. For example, Participant A considered 5 different bank accounts throughout the process (number of alternatives $=5$ ) and evaluated them taking into account their monthly fee, overdraft limit and overdraft charges (number of criteria $=3$ ). The number 
of alternatives and criteria is measured for each individual and used to develop the mean value and standard deviation for each archetype group. The consideration set is an important part of the purchase process [98], and may change during the process [3]. By increasing the number of alternatives, decision-making becomes more complex and tiresome $[18,86]$. The consideration set is dependent on individual characteristics and therefore varies between consumers [106]. The number of evaluation criteria has been studied for several decades [83, 105], including banking sector studies [75]. Decisions become more difficult where there are more criteria involved in the product choice because the complexity of the evaluation process increases.

\subsection{Measurements of individual characteristics}

Online shoppers were classified into four archetypes based on the decision making style and their knowledge of the market and products. As mentioned in section 3, we established maximization tendency using a measurement developed by Schwartz et al. [102], which includes 13 self-report items. It indicates an individual's "tendency to seek optimality" on a one dimensional satisfying-maximizing continuum. This measurement has previously been used by other researchers $[7,18,23,39,80,100]$.

Product knowledge was measured using an adaption of the Brucks model [11], who applies two items to measure the subjective knowledge of consumers about a product. The two questions used to establish knowledge of product require participants to rate their knowledge of product and familiarity with product category on a scale ranging from very high to very low. Brucks' model of subjective knowledge assesses individuals' perceptions. Such subjective knowledge defines the amount of search and evaluation style as it reflects consumers' own decisions on what actions should be taken $[11,101]$. The responses to the 2 items were combined and averaged to provide a single composite score. Due to the nature of question, the centre of the scale was used as a cut-off point.

The responses to the 13 items on the maximization scale and 2 items of knowledge showed good internal consistency (Cronbach's Alpha .84 and 0.79, respectively). 


\section{Results}

The analysis of the decision-making processes for the 55 participants included 3,083 activities in the UML activity diagrams and 1,907 transitions between different stages (roles). The data collection and analysis was therefore intensive in terms of detailed study of individual participants, and the sample size of 55 is large compared with previous similar studies.

Responses to the 13 items on the maximization scale (7-point Likert scale) were combined and averaged to provide a single composite score, ranging from 3.1 to 6.3 . The range was slightly narrower than that of Schwartz et al., from 2.6 to 6.7, [102]. Similar to Schwartz et al. [102], Iyengar et al. [54] and Love [73], a median split was used to differentiate between maximizers and satisficers. The median was 4.46 , slightly higher than the 4.2 reported by Schwartz et al. [102] and 4.15 in Love's sample [73]. The distribution of the maximization scores is similar to earlier studies [54, 102].

Table 3 shows the number of participants in each group.

\subsection{Descriptive data analysis}

The results of our descriptive data analysis (see Table 3 ) illustrate the variations in the behaviour of the four archetypes. Based on the descriptive statistics results, maximizers with low knowledge have the highest (41.54) number of cycles and satisficers with high knowledge the lowest number of cycles (23.83). Satisficers with low knowledge (33.79) are only marginally lower than maximizers with high knowledge (35.81). A similar pattern has emerged for the other three process-related outcomes i.e. duration, number of alternatives and number of criteria.

---Insert Table 3 around here---

As illustrated, satisficers (archetypes 1 and 2) engage in decision making processes with a lower number of cycles, a lower number of alternatives, a lower number of criteria and shorter duration compared to maximizers (archetypes 3 and 4 ). Within a decision 
making style, those with low level of knowledge engage in decision making processes with a higher number of cycles, a higher number of alternatives, a higher number of criteria and longer duration compared to those with high level of knowledge.

\subsection{Hypothesis testing}

Multivariate analysis of variance (MANOVA) was performed to test the statistical significance of archetype differences and illustrate variations in the intensity of the decision making process. The results are shown in Table 4. Based on the significance of multivariate analysis, the impact of archetype membership on each dependent variable was examined. Levene's tests indicated no violation of the homogeneity of variance assumption. The MANOVA results for the archetypes in Table 4 demonstrate that the archetype differences shown in Table 3 are statistically significant for all of the four process-related outcomes.

In addition, we have evaluated the relationship between the two independent variables (decision-making style and knowledge of product) and the four dependent variables and added the MANOVA results to Table 4. Decision making style has a significant effect on all dependent variables. Therefore, H1a, H1b, H1c, H1d are supported.

In the online purchase decision-making context, where many choices are present, maximizers and satisficers follow different processes. In line with the literature [20, 55, 72, 102], we have shown that maximizers perform more intensive decision making processes compared to satisficers. In order to make a purchase decision, they consider a larger number of alternatives and compare them all against a larger set of criteria. They constantly move between the options and spend more time evaluating them. These results illustrate that variations of decision-making behaviour between maximizers and satisficers in offline settings [102] also apply to the context of online purchase decision making processes.

Hypotheses $\mathrm{H} 2 \mathrm{a}, \mathrm{H} 2 \mathrm{~b}$ and $\mathrm{H} 2 \mathrm{c}$ are also supported. Knowledge of product has been shown to have a significant effect on duration, cycles and alternatives. Consumers with a high level of knowledge are selective in information search and processing [16] which leads to a less intensive decision-making process. Therefore this research is in line with a number of 
previous studies on knowledge of product [11, 21, 77] suggesting a negative relationship between knowledge and intensity of the decision making process.

However, there is no evidence to support $\mathrm{H} 2$ d, i.e., knowledge of product does not have a significant effect on the number of criteria considered $(\mathrm{p}=.25)$. This suggests that having a higher level of knowledge enhances the efficiency of the decision making process by reducing the number of cycles and duration and helping consumers focus on relevant alternatives only. However, there are no significant differences in terms of number of criteria considered between consumers of high level of knowledge compared to those with low level of knowledge. Indeed, consumers' perception of what they know does not affect the number of criteria taken into account when differentiating between alternatives [11]. Therefore, decision making style, and not knowledge of product, explains the variation in terms of number of criteria.

The above results can be used to explain the contradictory results of research into the effect of product knowledge on the search process reported in the literature $[6,62]$. In accordance with Malhotra [74], it is demonstrated that considering product knowledge with another individual characteristic provides more meaningful insights into search behaviour. Indeed, the decision making style of consumers indicates their motivational propensity for allocating effort to a purchase process, while their level of knowledge determines their searching abilities and amount of research required to reach a decision point. This leads to differential decision making behaviour for each archetype.

\subsection{Discussion of the banking and mobile network sectors}

Even though the exact nature of the differences between the two sectors is beyond the scope of this work, the following observations can be made. Within each archetype, consumers displayed similar types of behaviour, and there are significant differences between the archetypes. The two variables, decision-making style and product knowledge, are valid constructs to define a typology of online consumers. In both sectors, maximizers engage in more intensive decision-making processes and within maximizer and satisficer archetypes, 
those with low level of knowledge participate in more intensive processes. The results of the study concerning differences between the archetypes and impact of both maximization tendency and knowledge of the product on decision-making process outcomes are consistent across both sectors.

Purchase decision processes in banking and mobile networks are complex and iterative. Decision making processes in the two sectors have similar characteristics because both sectors offer high-involvement products that are of significant value to the consumer, which require active problem-solving and information seeking behaviour [34, 67, 78].

\section{Conclusions, limitations and future research}

This research has depicted the complexity of online purchase decision-making processes using detailed evidence from a sample of 55 consumers who took part in an intensive video-based study. It provided evidence for the dependence of decision-making outputs of number of cycles, time duration, number of alternatives and number of criteria on two independent variables, decision-making style and product knowledge. A typology was proposed using the constructs decision-making style and product knowledge to create four archetypes of online consumers. The intensity of the purchase decision-making behaviour of each archetype was examined for each archetype. The results indicated that the intensity of the process in terms of number of cycles, duration, number of alternatives and criteria were dependent on both decision-making style and product knowledge.

Satisficers with high knowledge conducted less intensive process whereas maximizers with low product knowledge conducted more intensive processes. Within both the maximizer and satisficer groups, the decision-making process is more intensive for those with low level of knowledge. These results are consistent with other studies that considered the influence of product knowledge on formulation [11, 21, 59] and search [76]. As a result, maximizers with low level of knowledge and satisficers with high level of knowledge have distinct behaviour and represent different forms of purchase decision-making characteristics. 
The research results therefore confirm the impact of decision-making style and product knowledge on consumer behaviour measured during a purchasing decision-making process. Their combination differentiated the decision-making behaviour into four distinct archetypes. This study is a development of previous research into decision-making style by including the impact of prior knowledge. The proposed typology that uses the constructs decision-making style and product knowledge has important theoretical and practical implications.

This work contributes to the consumer decision-making literature in its attempt towards segmentation of online consumers and by showing empirically that there are fundamental differences in the decision-making behaviour of each archetype of online consumer. This segmentation should be further explored. Moreover, this research is a broad study that explores the behaviour throughout all the stages of the online purchase process, rather than just focusing on the search stage.

This research contributes to the information system and e-business literatures by extending our understanding of online search and purchase behaviour. The results have particular significance on personalization and customization of Information systems content and design [42]. The introduction of the archetypes concept introduces a new theoretical contribution that provides a method of online segmentation that can be used to improve website personalization.

The managerial contribution of the research is that it offers insights to online retailers into possible segmentation strategies that have important implications for website design and the value of the product offer. By understanding different segments of consumers and variations in their behaviour, online retailers can identify the needs of each particular group and facilitate their decision-making processes on their websites. For example, maximizers perform a more intensive process to ensure the best choice. Offering tools that simplify the process and facilitate their decision-making can improve their experience by generating a more efficient and less time-consuming process. Those with a low level of knowledge reformulate their mental model of the decision problem more than others. They should therefore be presented with the main criteria at the beginning of their search process and be 
allowed flexibility to amend it as they progress in their online purchasing process. It will help them understand the concept earlier, reduce the number of reformulation cycles and simplify the buying process.

Experiments do have some limitations. Participants' behaviour might be affected by being aware of the video recorder. However, this issue is prevalent when its influence is in some way relevant to the aim of the study, which is not the case here. In an experiment, participants might behave slightly differently from how they would in a real-life setting. However, the design of the task aimed to reduce this effect by making the activity as realistic as possible and by posing a problem that all of the participants would recognise and be feasible to address. In addition, participants were told that there was no expected or favourable behaviour and they were given as little direction and as much freedom as possible. The benefits of this method outweighed its limitations for the purpose of this research. The sample size used in this research is quite large compared to reported sample sizes of intensive video recording studies in the literature. However, all of the participants were highly educated, and were all UK consumers. The implications of this for other contexts should be taken into account. The results are based on consumer behaviour in two sectors. This may be a potential limitation to the generalizability of the results. However, both market sectors are common in other European, US and Asian economies. There is also no reason to suppose that the two sectors are unusual in any way, especially given that the behavioural patterns observed in both sectors were very similar for each archetype. Future work however, could focus on products with different levels of user-involvement and decision making complexity.

The behaviour of four proposed segments was assessed in detail using both qualitative and quantitative methods. Two sectors were analysed in this research and relatively similar behaviour was observed for both, but as we noted above this should be tested in other sectors. Further research can also study the way e-businesses can support the decision-making process of each archetype of consumer considering their typology of behaviour. For example, the findings suggest that the archetype of maximizers with low level of knowledge require a high level of assistance as they tend to engage in complex decision-making processes. 


\section{Acknowledgments}

We are thankful to all subjects who participated in our study. We are also grateful to Yu-Lun

Liu for all his comments and support with this work.

\section{References}

1. R.S. Aguilar-Saven, Business process modelling: review and framework, International Journal of Production Economics 90 (2004) 129-149.

2. J.W. Alba, J.W. Hutchinson, Dimensions of consumer expertise, Journal of Consumer Research (1987) 411-454.

3. D. Ariely, D. Zakay, A timely account of the role of duration in decision making, Acta Psychologica 108 (2001) 187-207.

4. G. Balabanis, N.L. Reynolds, Consumer attitudes towards multi-channel retailers' web sites: the role of involvement, brand attitude, internet knowledge and visit duration, Journal of Business 18 (2001) 105-131.

5. R. Benbunan-Fich, Using protocol analysis to evaluate the usability of a commercial web site, Information \& Management 39 (2001) 151-163.

6. P.D. Bennett, R.M. Mandell, Prepurchase information seeking behavior of new car purchasers: the learning hypothesis, Journal of Marketing Research (1969) 430-433.

7. A.J. Bergman, J.E. Nyland, L.R. Burns, Correlates with perfectionism and the utility of a dual process model, Personality and Individual Differences 43 (2007) 389-399.

8. A. Besharat, D.M. Ladik, F.A. Carrillat, Are maximizers blind to the future? When today's best does not make for a better tomorrow, Marketing Letters, 25(1) (2014) 77-91.

9. J.R. Bettman, C.W. Park, Effects of prior knowledge and experience and phase of the choice process on consumer decision processes: a protocol analysis, Journal of Consumer Research 7 (1980) 234-248.

10. E. Bigne, C. Ruiz, S. Sanz, The impact of internet user shopping patterns and demographics on consumer mobile buying behaviour, Journal of Electronic Commerce Research 6 (2005) 193-209.

11. M. Brucks, The effects of product class knowledge on information search behavior, Journal of Consumer Research 12 (1985) 1-16.

12. J. Bughin, J. Doogan, O.J. Vetvik, A new way to measure word-of-mouth marketing, McKinsey Quarterly 3 (2010) 113-116.

13. M.D. Byrne, B.E. John, N.S. Wehrle, D.C. Crow, The tangled web we wove: a taskonomy of WWW use, in: Proceedings of the SIGCHI Conference on Human Factors in Computing Systems, ACM, New York, 1999, pp. 544-551.

14. C.A. Chang, R.R. Burke, Consumer choice of retail shopping aids, Journal of Retailing and Consumer Services 14 (2007) 339-346.

15. Y.L. Chang, S. Chen, C.C. Chen, I. Chen, Workflow process definition and their applications in e-commerce, in: Proceedings of the International Symposium on Multimedia Software Engineering, IEEE, 2000, pp. 193-200.

16. S.J. Chen, T.Z. Chang, A descriptive model of online shopping process: some empirical results, International Journal of Service Industry Management 14 (2003) 556-569.

17. C.M. Chiu, M.H. Hsu, H. Lai, C.M. Chang, Re-examining the influence of trust on online repeat purchase intention: the moderating role of habit and its antecedents, Decision Support Systems 53 (2012) 835-845. 
18. T.G. Chowdhury, S. Ratneshwar, P. Mohanty, The time-harried shopper: exploring the differences between maximizers and satisficers, Marketing Letters 20 (2009) 155-167.

19. B. T. Christensen and C. D. Schunn, The relationship of analogical distance to analogical function and preinventive structure: The case of engineering design, Memory \& cognition 35 (2007), 29-38.

20. E. Constantinides, Influencing the online consumer's behavior: the Web experience, Internet Research 14 (2004) 111-126.

21. E. Cowley, A.A. Mitchell, The moderating effect of product knowledge on the learning and organization of product information, Journal of Consumer Research 30 (2003) 443454.

22. W.K. Darley, C. Blankson, D.J. Luethge, Toward an integrated framework for online consumer behavior and decision making process: a review, Psychology and Marketing 27 (2010) 94-116.

23. I. Dar-Nimrod, C.D. Rawn, D.R. Lehman, B. Schwartz, The maximization paradox: the costs of seeking alternatives, Personality and Individual Differences 46 (2009) 631-635.

24. R. Decker, M. Trusov, Estimating aggregate consumer preferences from online product reviews, International Journal of Research in Marketing 27 (2010) 293-307.

25. C. Dennis, B. Merrilees, C. Jayawardhena, L.T. Wright, E-consumer behaviour, European Journal of Marketing 43 (2009) 1121-1139.

26. R. Dhar, S.J. Sherman, The effect of common and unique features in consumer choice, Journal of Consumer Research (1996) 193-203.

27. K. Diehl, C. Poynor, Great expectations?! Assortment size, expectations and satisfaction, Journal of Marketing Research 47 (2010) 312-322.

28. C. Dorn, T. Burkhart, D. Werth, S. Dustdar, Self-adjusting recommendations for peopledriven ad-hoc processes, Business Process Management (2010) 327-342.

29. P.J. Du Plessis, G.G. Rousseau, and N.H. Blem, Consumer Behaviour: A South African Perspective, Sigma, Pretoria, 1991.

30. J.F. Engel, D.T. Kollat, R.D. Blackwell, Consumer Behavior, New York: Holt, Rinehart and Winston, 1968. One of the earliest presentations of a cognitive model of consumer choice.

31. A.C. Erasmus, E. Boshoff, G.G. Rousseau, Consumer decision-making models within the discipline of consumer science: a critical approach, Journal of Family Ecology and Consumer Sciences/Tydskrif vir Gesinsekologie en Verbruikerswetenskappe 29 (2001) 82-90.

32. R. Eshuis, R. Wieringa, Verification support for workflow design with UML activity graphs, in: Proceedings of the 24th International Conference on Software Engineering, ACM, New York, 2002, pp. 166-176.

33. M.S. Featherman, P.A. Pavlou, Predicting e-services adoption: a perceived risk facets perspective, International Journal of Human-Computer Studies 59 (2003) 451-474.

34. D. W. Finn, Low involvement isn't low involving. Advances in Consumer Research, 10 (1983) 419-424.

35. S. French, J. Maule, N. Papamichail, Decision Behaviour, Analysis and Support, Cambridge University Press, 2009.

36. S. F. Gardial, D. S. Clemons, R. B. Woodruff, D. W. Schumann, M. J. Burns, Comparing consumers' recall of prepurchase and postpurchase product evaluation experiences, Journal of Consumer Research, (1994) 548-560.

37. S. Grabner-Kräuter, R. Faullant, Consumer acceptance of internet banking: the influence of internet trust, International Journal of Bank Marketing 26 (2008) 483-504. 
38. S. Grazioli, S.L. Jarvenpaa, Perils of Internet fraud: an empirical investigation of deception and trust with experienced Internet consumers, Systems, Man and Cybernetics, Part A: Systems and Humans, IEEE Transactions 30 (2002) 395-410.

39. J.G. Griffin, S.M. Broniarczyk, The slippery slope: the impact of feature alignability on search and satisfaction, Journal of Marketing Research 47 (2010) 323-334.

40. A. Gupta, B. Su, Z. Walter, An empirical study of consumer switching from traditional to electronic channels: A purchase-decision process perspective, International Journal of Electronic Commerce 8 (2004) 131-161.

41. J.M.C. Hernandez, J.A. Mazzon, Adoption of Internet banking: proposition and implementation of an integrated methodology approach, International Journal of Bank Marketing 25 (2007) 72-88.

42. Ho, S.Y., and Bodoff, D., The Effects of Web Personalization on User Attitude and Behavior: An Integration of the Elaboration Likelihood Model and Consumer Search Theory, MIS Quarterly 38 (2014) 497-520.

43. J. Holland, S.M. Baker, Customer participation in creating site brand loyalty, Journal of Interactive Marketing 15 (2001) 34-45.

44. C. Hölscher, G. Strube, Web search behavior of Internet experts and newbies, Computer Networks 33 (2000) 337-346.

45. O. Holschke, Impact of granularity on adjustment behavior in adaptive reuse of business process models, Business Process Management (2010) 112-127.

46. J. Holt, A Pragmatic Guide to Business Process Modelling, British Computer Society, Swindon, 2005.

47. S. Holtzman, Intelligent Decision Systems, Addison-Wesley, Reading, MA, 1989.

48. J.A. Howard, J.N. Sheth, The Theory of Buyer Behavior, John Wiley \& Sons, New York, 1969.

49. B. Howcroft, R. Hamilton, P. Hewer, Consumer attitude and the usage and adoption of home-based banking in the United Kingdom, International Journal of Bank Marketing 20 (2002) 111-121.

50. T.L. Hsia, J.H. Wu, E.Y. Li, The e-commerce value matrix and use case model: a goaldriven methodology for eliciting $\mathrm{B} 2 \mathrm{C}$ application requirements, Information \& Management 45 (2008) 321-330.

51. X. $\mathrm{Hu}, \mathrm{G} . \mathrm{Wu}, \mathrm{Y} . \mathrm{Wu}, \mathrm{H}$. Zhang, The effects of Web assurance seals on consumers' initial trust in an online vendor: a functional perspective, Decision Support Systems 48 (2010) 407-418.

52. R.K.F. Ip, C. Wagner, Weblogging: a study of social computing and its impact on organizations, Decision Support Systems 45 (2008) 242-250.

53. S.S. Iyengar, and W. Jiang, Choosing not to choose: the effect of more choices on retirement savings decisions, Columbia University working paper, 2004.

54. S.S. Iyengar, R.E. Wells, B. Schwartz, Doing better but feeling worse: looking for the "best" job undermines satisfaction, Psychological Science 17 (2006) 143-150.

55. C. Jayawardhena, P. Foley, Changes in the banking sector - the case of Internet banking in the UK, Internet Research 10 (2000) 19-31.

56. E.J. Johnson, S. Bellman, G.L. Lohse, Cognitive lock-in and the power law of practice, Journal of Marketing (2003) 62-75.

57. E.J. Johnson, W.W. Moe, P.S. Fader, S. Bellman, G.L. Lohse, On the depth and dynamics of online search behavior, Management Science 50 (2004) 299-308.

58. M.D. Johnson, Consumer choice strategies for comparing noncomparable alternatives, Journal of Consumer Research (1984) 741-753. 
59. K.P. Kaas, Consumer habit forming, information acquisition, and buying behavior, Journal of Business Research 10 (1982) 3-15.

60. S. Karimi, A purchase decision making process model of online consumers and its influential factors: A cross sector analysis, PhD Thesis, University of Manchester, 2012.

61. S. Karimi, K.N. Papamichail, C.P. Holland, Modelling consumer purchase decision making processes, working paper, 2012.

62. G. Katona, E. Mueller, A study of purchase decisions, in: L.H. Clarke (Ed.), Consumer Behavior: The Dynamics of Consumer Reaction, New York University Press, 1955, pp. 30-87.

63. D.J. Kim, D.L. Ferrin, H.R. Rao, A trust-based consumer decision-making model in electronic commerce: the role of trust, perceived risk, and their antecedents, Decision Support Systems 44 (2008) 544-564.

64. N.M. Klein, M.S. Yadav, Context effects on effort and accuracy in choice: an enquiry into adaptive decision making, Journal of Consumer Research (1989) 411-421.

65. M. Koufaris, Applying the technology acceptance model and flow theory to online consumer behavior, Information Systems Research 13 (2003) 205-223.

66. A.W. Kushniruk, V.L. Patel, Cognitive evaluation of decision making processes and assessment of information technology in medicine, International Journal of Medical Informatics 51 (1998) 83-90.

67. J.L. Lastovicka, Questioning the concept of involvement defined product classes. Advances in Consumer Research, 6 (1979) 174-179.

68. A. Langley, Strategies for theorizing from process data, Academy of Management Review 24 (1999) 691-710.

69. A. Langley, H. Mintzberg, P. Pitcher, E. Posada, J. Saint-Macary, Opening up decision making: the view from the black stool, Organization Science 6 (1995) 260-279.

70. P.M. Lee, Behavioral model of online purchasers in e-commerce environment, Electronic Commerce Research 2 (2002) 75-85.

71. P. Levinson, Cellphone: The Story of the World's Most Mobile Medium and How It Has Transformed Everything!', Palgrave Macmillan, New York, 2004.

72. Y.-L. Liu, K.A. Keeling, K. N. Papamichail, Should retail trade companies avoid recruiting maximisers? Management Decision, 53 (2015) 730-750.

73. R.W.B. Love, Maximizing and relationships, MA thesis, University of Texas at Austin, 2009.

74. N.K. Malhotra, On individual differences in search behavior for a nondurable, Journal of Consumer Research 10 (1983) 125-131.

75. R. Martenson, Consumer choice criteria in retail bank selection, International Journal of Bank Marketing 3 (1985) 64-74.

76. W.L. Moore, D.R. Lehmann, Individual differences in search behavior for a nondurable, Journal of Consumer Research 7 (1980) 296-307.

77. C. Moorman, K. Diehl, D. Brinberg, B. Kidwell, Subjective knowledge, search locations and consumer choice, Journal of Consumer Research 31 (2004) 673-680.

78. S. Moorthy, B.T., Ratchford, D. Talukdar, Consumer information search revisited: Theory and empirical analysis. Journal of Consumer Research, 23 (1997) 263-277.

79. F.M. Nicosia, R.N. Mayer, Toward a sociology of consumption, Journal of Consumer Research 3 (1976) 65-75.

80. A. Oulasvirta, J.P. Hukkinen, B. Schwartz, When more is less: the paradox of choice in search engine use, in: Proceedings of the 32nd International ACM SIGIR Conference on Research and Development in Information Retrieval, ACM, New York, 2009, pp. 516523. 
81. K.N. Papamichail, I. Robertson, Integrating decision making and regulation in the management control process, Omega 33 (2005) 319-332.

82. K.N. Papamichail, I. Robertson, Supporting distributed decision processes using an evolution model, Operational Research 8 (2008) 279-297.

83. C.W. Park, R.J. Lutz, Decision plans and consumer choice dynamics, Journal of Marketing Research (1982) 108-115.

84. P.A. Pavlou, H. Liang, Y. Xue, Understanding and mitigating uncertainty in online exchange relationships: a principal-agent perspective, Management Information Systems Quarterly 31 (2007) 105-136.

85. J.W. Payne, J.R. Bettman, E.J. Johnson, Adaptive strategy selection in decision making, Journal of Experimental Psychology: Learning, Memory, and Cognition 14 (1988) 534552.

86. J.W. Payne, J.R. Bettman, E.J. Johnson, The Adaptive Decision Maker, Cambridge University Press, 1993.

87. R. Petrusel, D. Mican, Mining decision activity logs, in: W. Abramowicz, R. Tolksdorf, K. Węcel (Eds), Business Information Systems Workshops, Springer, Berlin and Heidelberg, 2010, pp. 67-79.

88. L. Petruzzellis, Mobile phone choice: technology versus marketing. The brand effect in the Italian market, European Journal of Marketing 44 (2010) 610-634.

89. E. Polman, Why are maximizers less happy than satisficers? Because they maximize positive and negative outcomes, Journal of Behavioral Decision Making, 23(2) (2010) 179-190.

90. T. Pikkarainen, K. Pikkarainen, H.P.S. Karijaluoto, Customer acceptance of on-line banking: an extension of the technology acceptance model, Internet Research 3 (2004) 224-235.

91. C. Ranaweera, G. McDougall, H. Bansal, A model of online customer behavior during the initial transaction: moderating effects of customer characteristics, Marketing Theory 5 (2005) 51-74.

92. R. Ranyard, W.R. Crozier, O. Svenson, Decision Making: Cognitive Models and Explanations, Routledge, London, 1997.

93. A.R. Rao, K.B. Monroe, The moderating effect of prior knowledge on cue utilization in product evaluations, Journal of Consumer Research 15 (1988) 253-264.

94. A.R. Rao, W.A. Sieben, The effect of prior knowledge on price acceptability and the type of information examined, Journal of Consumer Research 19 (1992) 256-270.

95. P.J. Regan, S. Holtzman, R\&D decision advisor: an interactive approach to normative decision system model construction, European Journal of Operational Research 84 (1995) 116-133.

96. H. Reijers, J. Mendling, Modularity in process models: review and effects, Business Process Management (2008) 20-35.

97. C. Rickwood, L. White, Pre-purchase decision-making for a complex service: retirement planning, Journal of Services Marketing 23 (2009) 145-153.

98. J.H. Roberts, J.M. Lattin, Development and testing of a model of consideration set composition, Journal of Marketing Research (1991) 429-440.

99. M. Sathye, Adoption of Internet banking by Australian consumers: an empirical investigation, International Journal of Bank Marketing 17 (1999) 324-334.

100. B. Scheibehenne, R. Greifeneder, P.M. Todd, What moderates the too much choice effect?, Psychology and Marketing 26 (2009) 229-253.

101. J.B. Schmidt, R.A. Spreng, A proposed model of external consumer information search, Journal of the Academy of Marketing Science 24 (1996) 246-256. 
102. B. Schwartz, A. Ward, J. Monterosso, S. Lyubomirsky, K. White, D.R. Lehman, Maximizing versus satisficing: happiness is a matter of choice, Journal of Personality and Social Psychology 83 (2002) 1178-1197.

103. S.G. Scott, R.A. Bruce, Decision-making style: the development and assessment of a new measure, Educational and Psychological Measurement 55 (1995) 818-831.

104. A. Sen, A.S. Vinze, Understanding the complexity of the model formulation process: a protocol analysis approach, Decision Sciences 28 (1997) 443-473.

105. J.N. Sheth, P.S. Raju, Sequential and cyclical nature of information processing models in repetitive choice behavior, Advances in Consumer Research 1 (1974) 348-358.

106. A.D. Shocker, M. Ben-Akiva, B. Boccara, P. Nedungadi, Consideration set influences on consumer decision-making and choice: issues, models, and suggestions, Marketing Letters 2 (1991) 181-197.

107. P. Shukla, Effects of perceived sacrifice, quality, value, and satisfaction on behavioral intentions in the service environment, Services Marketing Quarterly 31 (2010) 466-484.

108. H.A. Simon, The New Science of Management Decisions, Harper and Row, New York, 1960.

109. A.D. Smith, W.T. Rupp, Strategic online customer decision making: leveraging the transformational power of the Internet, Online Information Review 27 (2003) 418-432.

110. S. Sproule, N. Archer, A buyer behaviour framework for the development and design of software agents in e-commerce. Internet Research. 10 (2000) 396-405.

111. I.S. Terpsidis, A. Moukas, B. Pergioudakis, G. Doukidis, P. Maes, The potential of electronic commerce in re-engineering consumer-retail relationships through intelligent agents, in: J.-Y. Roger, B. Stanford-Smith, P.T. Kidd (Eds), Advances in Information Technologies: The Business Challenge, IOS Press, Amsterdam, 1997, pp. 311-318.

112. D. R. Thomas, A general inductive approach for analyzing qualitative evaluation data American Journal of Evaluation 27 (2006) 237-246

113. H. Thorbjornsen, M. Supphellen, The impact of brand loyalty on website usage, Journal of Brand Management 11 (2004) 199-208.

114. P. Todd, I. Benbasat, Process tracing methods in decision support systems research: exploring the black box, Management Information Systems Quarterly (1987) 493-512.

115. P.W. Turnbull, S. Leek, G. Ying, Customer confusion: the mobile phone market, Journal of Marketing Management 16 (2000) 143-163.

116. H. Van der Heijden, T. Verhagen, M. Creemers, Understanding online purchase intentions: contributions from technology and trust perspectives, European Journal of Information Systems 12 (2003) 41-48.

117. Y.S. Wang, Y.M. Wang, H.H. Lin, T.I. Tang, Determinants of user acceptance of Internet banking: an empirical study, International Journal of Service Industry Management 14 (2003) 501-519.

118. B.C. Warboys, P. Kawalek, I. Robertson, M. Greenwood, Business Information Systems: A Process Approach, McGraw-Hill, Maidenhead, 1999.

119. L.R. Weingart, How did they do that? The ways and means of studying group processes, Research in Organizational Behavior 19 (1997) 189-240.

120. L. Xia, D. Sudharshan, Effects of interruptions on consumer online decision processes, Journal of Consumer Psychology 12 (2002) 265-280.

121. A. Zafar, UK retail banking keywords hit $2.4 \mathrm{~m}$ on Google, Financial Times, 12 January 2012. 


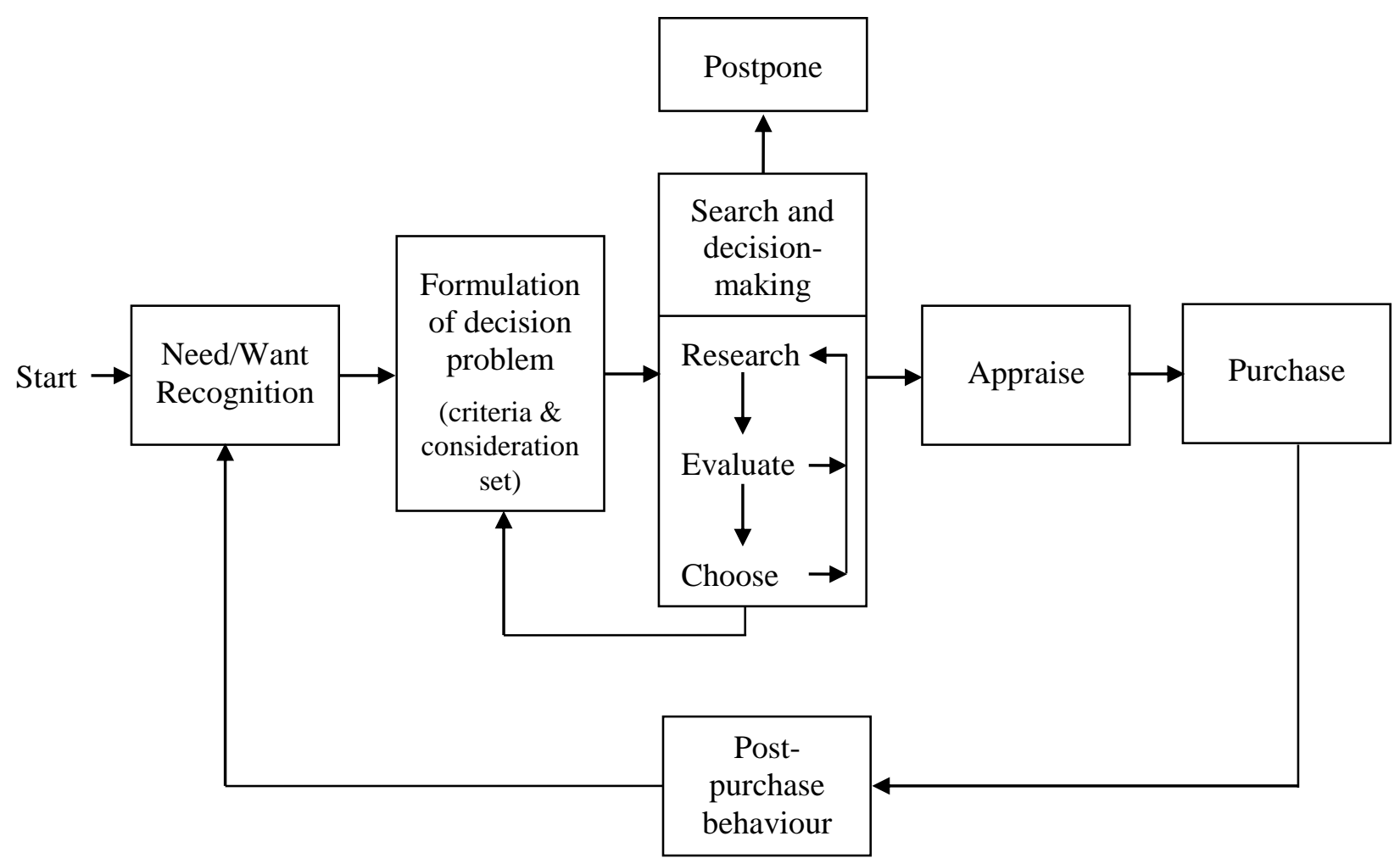

Fig. 1. Consumer purchase decision-making framework 


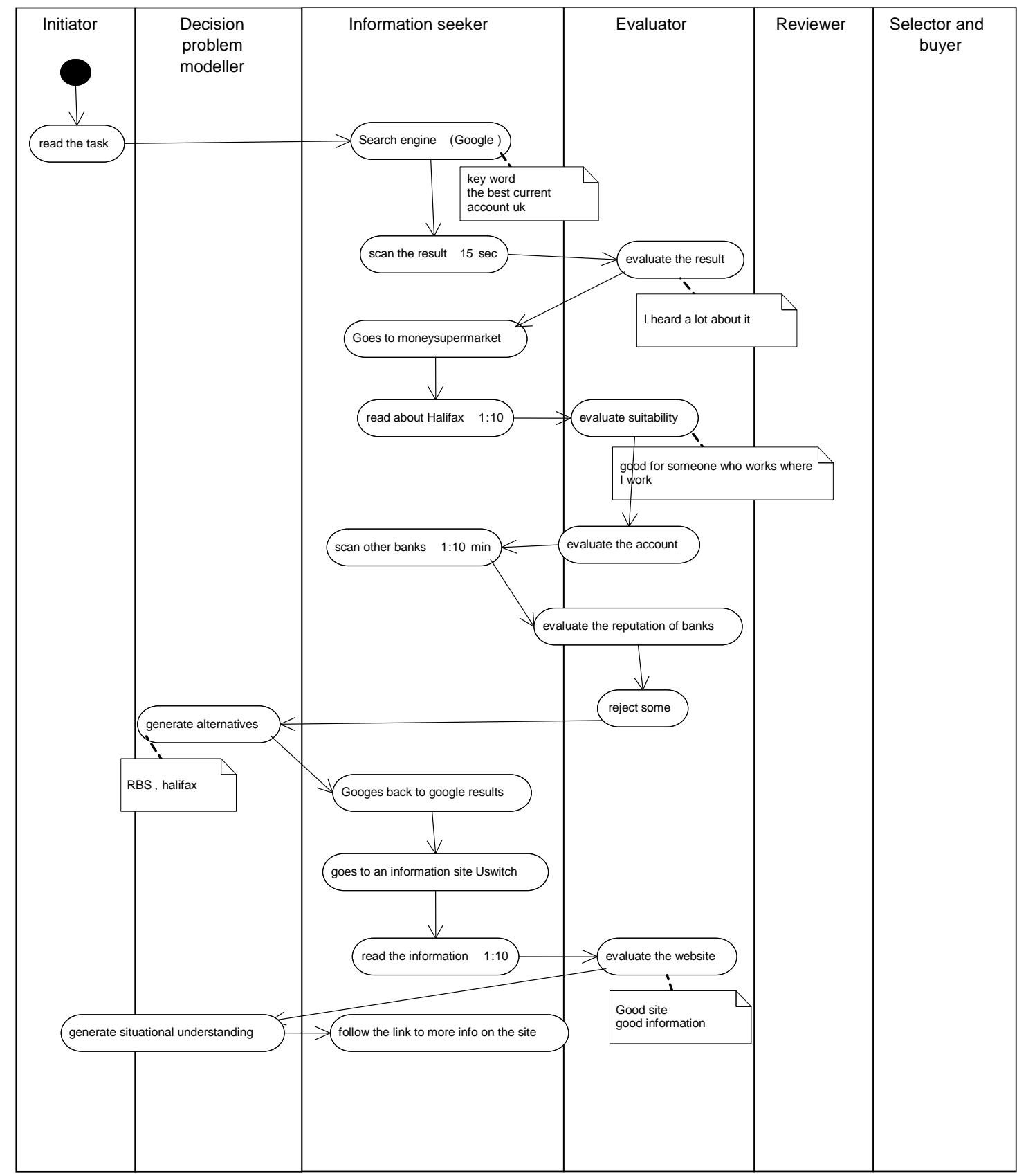

Fig. 2. Part of a process model instance for one individual 


\section{List of Tables}

Table 1

Four archetypes of online consumers

\begin{tabular}{|c|c|c|}
\hline \multirow{2}{*}{$\begin{array}{c}\text { Decision-Making } \\
\text { Style }\end{array}$} & \multicolumn{2}{|c|}{ Knowledge of Product } \\
\hline & Low & High \\
\hline \multirow[b]{2}{*}{ Satisficer } & Archetype 1: & Archetype 2: \\
\hline & $\begin{array}{l}\text { Satisficer with low } \\
\text { knowledge of product }\end{array}$ & $\begin{array}{l}\text { Satisficer with high } \\
\text { knowledge of product }\end{array}$ \\
\hline \multirow[b]{2}{*}{ Maximizer } & Archetype 3: & Archetype 4: \\
\hline & $\begin{array}{l}\text { Maximizer with low } \\
\text { knowledge of product }\end{array}$ & $\begin{array}{l}\text { Maximizer with high } \\
\text { knowledge of product }\end{array}$ \\
\hline
\end{tabular}

Table 2

Stages of the purchase decision-making process and corresponding roles

\begin{tabular}{|c|c|c|}
\hline $\begin{array}{l}\text { Stages of online } \\
\text { purchase decision- } \\
\text { making process }\end{array}$ & $\begin{array}{l}\text { Roles associated with } \\
\text { each stage }\end{array}$ & Description of roles \\
\hline Need recognition & Initiator & Initiate the process \\
\hline Formulation & $\begin{array}{l}\text { Decision problem } \\
\text { modeller }\end{array}$ & $\begin{array}{l}\text { Develop the mental model of the } \\
\text { decision problem }\end{array}$ \\
\hline Information research & Information seeker & $\begin{array}{l}\text { Find reliable information that is } \\
\text { required for decision-making }\end{array}$ \\
\hline Evaluation & Evaluator & $\begin{array}{l}\text { Evaluate and compare sources, } \\
\text { information and products }\end{array}$ \\
\hline Appraisal & Reviewer & $\begin{array}{c}\text { Double-check the process and } \\
\text { alternatives }\end{array}$ \\
\hline Choice & Selector & $\begin{array}{l}\text { Select the best option among the } \\
\text { alternatives }\end{array}$ \\
\hline
\end{tabular}


Table 3

Descriptive statistics

\begin{tabular}{|c|c|c|c|c|}
\hline \multirow{2}{*}{ Dependent variables } & \multicolumn{4}{|c|}{ Archetype means (standard deviation) } \\
\hline & Archetype 1 & Archetype 2 & Archetype 3 & Archetype 4 \\
\hline Number of cycles & $33.79(10.27)$ & $23.83(6.32)$ & $41.54(7.04)$ & $35.81(17.43)$ \\
\hline Duration & $20.43(7.55)$ & $15.08(5.32)$ & $29.23(9.35)$ & $21.94(9.03)$ \\
\hline $\begin{array}{l}\text { Number of } \\
\text { alternatives }\end{array}$ & $5.36(1.74)$ & $3.25(0.87)$ & $8.08(2.02)$ & $6.13(2.36)$ \\
\hline Number of criteria & $3.79(0.97)$ & $3.25(0.97)$ & $4.77(1.59)$ & $4.50(1.41)$ \\
\hline \\
\hline \multicolumn{2}{|c|}{ Archetype 2: Satisficer with high knowledge of product $(\mathrm{N}=12)$} & \multicolumn{3}{|c|}{ Archetype 3: Maximizer with low knowledge of product $(\mathrm{N}=13)$} \\
\hline \multicolumn{5}{|c|}{ Archetype 4: Maximizer with high knowledge of product $(\mathrm{N}=16)$} \\
\hline
\end{tabular}

Table 4 MANOVA results (F-values)

\begin{tabular}{|c|c|c|c|c|c|}
\hline & & $\begin{array}{c}\text { Numbe } \\
\mathrm{r} \text { of } \\
\text { cycles }\end{array}$ & Duration & $\begin{array}{l}\text { Number of } \\
\text { alternatives }\end{array}$ & $\begin{array}{c}\text { Number } \\
\text { of criteria }\end{array}$ \\
\hline \multirow[t]{2}{*}{ Archetypes } & & $\begin{array}{l}4.961^{* *} \\
\left(.226^{\mathrm{a}}\right)\end{array}$ & $\begin{array}{l}6.577^{* *} \\
\left(.279^{\mathrm{a}}\right)\end{array}$ & $\begin{array}{c}14.136^{* *} \\
\left(.454^{\mathrm{a}}\right)\end{array}$ & $\begin{array}{l}3.779^{*} \\
\left(.182^{\mathrm{a}}\right)\end{array}$ \\
\hline & $\begin{array}{l}\text { Levene's } \\
\text { test (Sig.) }\end{array}$ & .194 & .292 & .088 & .150 \\
\hline $\begin{array}{l}\text { Decision } \\
\text { making style }\end{array}$ & & $9.693^{* *}$ & $12.786^{* *}$ & $30.124^{* *}$ & $10.430^{* *}$ \\
\hline $\begin{array}{l}\text { Knowledge of } \\
\text { product }\end{array}$ & & $6.119^{*}$ & $8.332^{*}$ & $15.856^{* *}$ & 1.355 \\
\hline
\end{tabular}

